\title{
Correspondence
}

\section{Cimetidine as an Organic Cation Transporter Antagonist}

\section{To the Editor-in-Chief:}

The recent article by Ciarimboli et al ${ }^{1}$ reports for the first time that the organic cation transporter 2 (OCT2) is present in hair cells of the cochlea in mice. They nicely showed that no ototoxicity occurred after cisplatin administration in OCT2 knockout mice as opposed to wild-type mice. They also used coadministration with the organic cation antagonist cimetidine and observed protection from ototoxicity, which we would like to discuss in more detail.

Platinum drugs have a large propensity to react with soft nucleophiles, eg, sulfur compounds, and this type of interaction has been the focus of a multitude of studies. $^{2-7}$ Recently, Buss et al ${ }^{8}$ showed that oxaliplatin rapidly interacts chemically with cimetidine, a thioether-containing drug, with a concomitant drastic reduction of the cytotoxicity of the platinum drug. The rate constant for the interaction of cisplatin with the thioether compound methionine is about half of the value reported for oxaliplatin, ${ }^{7}$ and we have established that this also holds for cimetidine (unpublished observations). Taking the chemical reactivity of cimetidine into account, two alternative hypotheses can be formulated concerning the otoprotective effect of the drug:

First, in the paper by Ciarimboli et al, ${ }^{1}$ cimetidine was given i.p. immediately before i.p. cisplatin. We do not know how fast the drugs are absorbed to the general circulation, ie, we do no not know if part of the dose of cisplatin is consumed by reaction with cimetidine in the peritoneal space or if there is a chemical interaction between the drugs systemically. We have previously studied the interaction between cisplatin and the otoprotector methionine in a guinea pig model. ${ }^{9}$ Administration of methionine i.v. caused a $30 \%$ decrease in the area under the concentration-time curve (AUC) of cisplatin. Dose adjustment of cisplatin in animals receiving methionine, ie, to obtain similar AUC as compared with the saline control group, resulted in similar ototoxicity in the two groups. It was concluded that the protective effect of methionine was explained by a lowered systemic exposure of cisplatin.

Second, because of the presence of OCT2 in the cochlea, one can envisage that the protective effect of cimetidine depends on an accumulation of the drug in critical parts of the cochlea ie, the hair cells and stria vascularis in the lateral wall, and that the protective effect is due to chemical neutralization of cisplatin in these parts. The ototoxicity is highly dependent on cisplatin exposure (AUC) in the perilymphatic compartment. A decrease in AUC from 515 to $202 \mu \mathrm{mol} / \mathrm{L} \times$ min completely abolished the ototoxicity. ${ }^{10}$ It should also be pointed out that the in vivo transformation product, the monohydrated complex of cisplatin, is more ototoxic than the parent compound. ${ }^{11}$ The chemical reactivity of this complex with sulfur compounds is even higher as compared with cisplatin. ${ }^{6}$

It should be highly interesting to compare the otoprotective effect of cimetidine with other candidates where no chemical interaction can occur. ${ }^{12}$

Hans Ehrsson

Karolinska Pharmacy and Karolinska Institutet

Stockholm, Sweden

Karolinska Pharmacy, Stockholm, Sweden

Inger Wallin

\section{References}

1. Ciarimboli G, Deuster D, Knief A, Sperling M, Holtkamp M, Edemir B, Pavenstädt H, Lanvers-Kaminsky C, Zehnhoff-Dinnesen A, Schinke $\mathrm{AH}$, Koepsell H, Jürgens $\mathrm{H}$, Schlatter E: Organic cation transporter 2 mediates cisplatin-induced oto- and nephrotoxicity and is a target for protective interventions. Am J Pathol 2010, 176:1-12

2. Corden BJ: Reaction of platinum(II) antitumor agents with sulfhydral compounds and the implications for nephrotoxicity. Inorg Chim Acta 1987, 137:125-130

3. El-Khateeb M, Appleton TG, Gahan LR, Charles BG, Berners-Price SJ, Bolton A-M: Reactions of cisplatin hydrolytes with methionine, cystein, and plasma ultrafiltrate studied by a combination of HPLC and NMR techniques. J Inorg Biochem 1999, 77:13-21

4. Dabrowiak JC, Goodisman J, Souid A-K: Kinetic study of the reaction of cisplatin with thiols. Drug Metab Disp 2002, 30:1378-1384

5. Verschraagen M, Kedde MA, Hausheer FH, van der Vijgh WJF: The chemical reactivity of BNP7787 and its metabolite mesna with the cytostatic agent cisplatin: comparison with the nucleophiles thiosulfate, DDTC, glutathione and its disulphide GSSG. Cancer Chemother Pharmacol 2003, 51:499-504

6. Videhult P, Laurell G, Wallin I, Ehrsson $\mathrm{H}$ : Kinetics of cisplatin and its monohydrated complex with sulphur-containing compounds designed for local otoprotective administration. Exp Biol Med 2006, 231:1638-1645 
7. Jerremalm E, Wallin I, Yachnin J, Ehrsson H: Oxaliplatin degradation in the presence of important biological sulphur-containing compounds and plasma ultrafiltrate. Eur J Pharm Sci 2006, 28:278-283

8. Buss I, Kalayda GV, Marques-Gallego P, Reedijk J, Jaehde U: Influence of the hOCT2 inhibitor cimetidine on the cellular accumulation and cytotoxicity of oxaliplatin. Int $\mathrm{J}$ Clin Pharmacol Ther 2009, 47:51-54

9. Ekborn A, Laurell G, Johnström P, Wallin I, Eksborg S, Ehrsson H: D-Methionine and cisplatin ototoxicity in the guinea pig: D-methionine influences cisplatin pharmacokinetics. Hear Res 2002, 165:53-61

10. Hellberg V, Wallin I, Eriksson S, Hernlund E, Jerremalm E, Berndtsson M, Eksborg S, Arnér ESJ, Shoshan M, Ehrsson H, Laurell G: Cisplatin and oxaliplatin toxicity: importance of cochlear kinetics as a determinant for ototoxicity. J Natl Cancer Inst 2009, 101:37-47

11. Ekborn A, Lindberg A, Laurell G, Wallin I, Eksborg S, Ehrsson H: Ototoxicity, nephrotoxicity and pharmacokinetics of cisplatin and its monohydrated complex in the guinea pig. Cancer Chemother Pharmacol 2003, 51:36-42

12. Suhre WM, Ekins S, Chang C, Swaan PW, Wright SH: Molecular determinants of substrate/inhibitor binding to the human and rabbit renal organic cation transporters hOCT2 and rbOCT2. Mol Pharmacol 2005, 67:1067-1077

\section{Author's Reply:}

Ehrson and Wallin critically discuss in their response to our work, where we showed that the presence of the organic cation transporter 2 (OCT2) in the mouse cochlea is critical for the development of cisplatin-induced ototoxicity, the mechanism by which cotreatment of animals with cimetidine leads to protection against cisplatin ototoxicity. They suggest that cimetidine leads to chemical neutralization of cisplatin and thereby reduces its ototoxic effects, rather than competes with cisplatin uptake via OCT2, as suggested in our paper. They base their suggestion on published data demonstrating such neutralization of cisplatin by cimetidine in vitro. This observation certainly needs critical consideration when interpreting our results. However, we presented at least two findings that argue against such an interpretation.

1) In experiments with MOLT4 cells, which do not express OCT2, cell toxicity of cisplatin was not different among cells that were incubated with cisplatin alone or with cisplatin and cimetidine in equimolar amounts (see Figure $8, A$ and B). Similar findings had been recently published by others, showing that coincubation of cells that do not express significant amounts of OCT2 with cisplatin and cimetidine did not change cisplatin toxicity. ${ }^{1}$

2) Treatment of animals with cimetidine was fully effective in protecting from cisplatin ototoxicity, but only partially effective in protecting the kidney, as shown for example in Figure 1B, where a significant polyuria is observed in the presence of cimetidine. If this protection were due to chemical neutralization by cimetidine, it should work similarly in both organs.

In contrast to these observations, in several studies an interaction of platinum derivatives with soft nucleophiles, such as methionine, glutathione, cysteine, and cimetidine, is reported. A possible explanation of this apparent discrepancy may come from the consideration that these studies are generally conducted using a large excess of nucleophiles. For example, in their cytotoxicity experiments, Buss et $\mathrm{al}^{2}$ used $20 \mu \mathrm{mol} / \mathrm{L}$ oxaliplatin with 1.5 $\mathrm{mmol} / \mathrm{L}$ cimetidine and, in their chemical interaction experiments, $10 \mathrm{mmol} / \mathrm{L}$ oxaliplatin with $150 \mathrm{mmol} / \mathrm{L}$ cimetidine. Jerremalm et $\mathrm{al}^{3}$ used $60 \mu \mathrm{mol} / \mathrm{L}$ oxaliplatin in 9.9 $\mathrm{mmol} / \mathrm{L}$ glutathione for their degradation studies. Moreover, in an in vivo approach, chemical interaction was investigated in guinea pig receiving $8 \mathrm{mg} / \mathrm{kg}$ cisplatin and $300 \mathrm{mg} / \mathrm{kg}$ methionine. ${ }^{4}$

In our model, cisplatin and cimetidine were used at the same molecular concentrations (giving origin to doses of 15 and $12.6 \mathrm{mg} / \mathrm{kg}$, respectively). Assuming that all of the administered drugs enter the circulation, one could expect a maximal blood concentration of $0.23 \mathrm{mg} / \mathrm{ml}$ cisplatin and $0.19 \mathrm{mg} / \mathrm{ml}$ cimetidine in a mouse with $30 \mathrm{~g}$ bodyweight. However, mouse body fluids and, in particular, blood contain physiological concentrations of glutathione ${ }^{5}$ and cysteine, ${ }^{6}$ which are higher $(1$ and $0.4 \mathrm{mg} / \mathrm{ml}$ blood, respectively) than the maximally expected cimetidine concentration in our experiments. Thus, if chemical neutralization of cisplatin by cimetidine is involved in our experiments in vivo, its contribution is certainly less important.

We agree with Ehrson and Wallin that it is of high interest to compare in vivo protective effects of cimetidine with other candidates where no chemical interaction can occur. However, it is certainly necessary to investigate whether the chemical inactivation of cisplatin observed in the studies mentioned by Ehrson and Wallin is also relevant in vivo with the doses used in our study. In addition, it is of primary importance to identify which form of cisplatin (cisplatin, monohydrated complex) is the substrate transported by OCTs.

In conclusion, we are convinced that the evidence presented in our publication on the one hand and the considerably higher concentrations used in the in vitro studies on the other hand support our interpretation of the mechanism of protection form cisplation toxicity by cimetidine.

Giuliano Ciarimboli Eberhard Schlatter

Universitätsklinikum Münster

Münster, Germany

\section{References}

1. More SS, Li S, Yee SW, Chen L, Xu Z, Jablons DM, Giacomini KM: Organic cation transporters modulate the uptake and cytotoxicity of picoplatin, a third-generation platinum analogue. Mol Cancer Ther 2010, 9:1058-1069

2. Buss I, Kalayda GV, Marques-Gallego P, Reedijk J, Jaehde U: Influence of the hOCT2 inhibitor cimetidine on the cellular accumulation and cytotoxicity of oxaliplatin. Int J Clin Pharmacol Ther 2009, 47:51-54

3. Jerremalm E, Wallin I, Yachnin J, Ehrsson $\mathrm{H}$ : Oxaliplatin degradation in the presence of important biological sulphur-containing compounds and plasma ultrafiltrate. Eur J Pharm Sci 2006, 28:278-283

4. Ekborn A, Laurell G, Johnstrom P, Wallin I, Eksborg S, Ehrsson H: $\mathrm{D}-$ Methionine and cisplatin ototoxicity in the guinea pig: D-methionine influences cisplatin pharmacokinetics. Hear Res 2002, 165:53-61

5. Khynriam D, Prasad SB: Hematotoxicity and blood glutathione levels after cisplatin treatment of tumor-bearing mice. Cell Biol Toxicol 2001 17:357-370

6. Yang G, Wu L, Jiang B, Yang W, Qi J, Cao K, Meng Q, Mustafa AK, Mu W, Zhang S, Snyder SH, Wang R: H2S as a physiologic vasorelaxant: hypertension in mice with deletion of cystathionine gamma-lyase. Science 2008, 322:587-590 